\title{
Investigation of the Wetting Properties of Ternary Lead-Free Solder Alloys on Copper Substrate
}

\author{
F. OMAÇ, ${ }^{a, *}$ D. OzYUREK ${ }^{a}$ AND M. ERER ${ }^{b}$ \\ ${ }^{a}$ Karabuk University, Technology Faculty, Manufacturing Eng., 78100 Karabuk, Turkey \\ ${ }^{b}$ Karabuk University, Science Faculty of Physics, 78100 Karabuk, Turkey
}

\begin{abstract}
In the present study, wetting behaviors of $\mathrm{Sn}-9 \mathrm{Zn}-x \mathrm{Al}$ ternary lead-free solder alloys produced by the addition of $\mathrm{Al}$ in various amounts binary $\mathrm{Sn}-9 \mathrm{Zn}$ eutectic lead-free solder alloy (wt\%) were investigated. Contact angles of alloys were measured by using of the sessile drop method. Microstructures, inter-metallic phases, and melting temperatures of alloys were characterized by optic microscope and scanning electron microscope and energy dispersive X-ray spectroscopy, X-ray diffraction, and differential scanning calorimeter, and effects of the amount of Al on microstructure were investigated. As a result, the studies show that Al-rich areas were found on microstructure of $\mathrm{Sn}-9 \mathrm{Zn}-x \mathrm{Al}$ alloys. The lowest melting temperature for $\mathrm{Sn}-9 \mathrm{Zn}-0.5 \mathrm{Al}$ and $\mathrm{Sn}-9 \mathrm{Zn}-0.7 \mathrm{Al}$ alloys was determined as $200.9^{\circ} \mathrm{C}$. It was determined that wetting capability of $\mathrm{Sn}-9 \mathrm{Zn}-x \mathrm{Al}$ alloys failed because of oxidation.
\end{abstract}

DOI: 10.12693/APhysPolA.131.165

PACS/topics: $81.05 . \mathrm{Bx}$

\section{Introduction}

Within the precautions taken by numbers of countries around the world to prevent environmental pollution, the European Union (EU) banned various pollutant materials after $2006[1,2]$. Therefore, instead of $\mathrm{Sn}-\mathrm{Pb}$ lead solder alloys utilized by the electronic industry as a solder material, necessary efforts are spent in development of alternative alloys. In available studies, since melting temperature was reported at a point close to the eutectic Sn$\mathrm{Pb}$ alloy $\left(198^{\circ} \mathrm{C}\right)$ and they have low-cost, $\mathrm{Sn}-9 \mathrm{Zn}$ leadfree solder alloys were taken into consideration [3]. Sn-Zn alloys have now been comparable with $\mathrm{Sn}-\mathrm{Pb}$ alloys in terms of melting temperature and mechanical properties. Nevertheless, resistances of $\mathrm{Sn}-\mathrm{Zn}$ alloys against oxidation and corrosion were low $[4,5]$. Owing to its diffusion and heating capabilities, tin constitutes basic component of majority of solder alloys used in electronic applications. When general properties of Sn-Zn alloys are taken into consideration, their superior solder capability and their harmless nature for human health increase attention toward usage these alloys in the industry. Soldering is the process of combination of two or more metal components by a filler metal with low melting temperature. Wetting or wettability is defined as diffusion tendency of the liquid phase on solid surface and this diffusion capability is determined by the contact angle between the two surfaces [6]. Therefore, in the present study, wetting performances of various alloys produced by addition of different amounts of aluminum into the $\mathrm{Sn}-9 \mathrm{Zn}$ eutectic alloys was investigated.

\section{Materials and method}

In this study, while different amounts $(0.5-0.9 \%)$ aluminum into the eutectic Sn-9Zn alloy were added, new

*corresponding author; e-mail: fatma.omac@gmail.com lead-free solder alloys were produced. In determination of wetting behavior of these alloys, $99.85 \%$ pure electrolytic copper substrate were used. The sessile drop method was used in the wetting tests. By means of this method, the $\mathrm{Sn}-9 \mathrm{Zn}-x \mathrm{Al}$ solder alloy was dropped on copper substrate at various temperatures of $215^{\circ} \mathrm{C}, 230^{\circ} \mathrm{C}$, and $250^{\circ} \mathrm{C}$. Casio Made Pro EX-F1, 600 FPS Model camera employed to capture views of drops at the 5th, 10th, 15th, 30th, 60th, 90th, 120th, and 150th seconds and these images were transferred into Corel Draw X5 Software to measure contact angles of each drop from the right and left profiles. As a result of these processes repeated for each temperature, mean angle values were calculated and new diagrams were drawn through the Sigma Plot 11.0 Software. In order to determine melting temperatures of alloys, the DSC analysis were carried out on specimens in maximum $30 \mathrm{mg}$ weight and at $40^{\circ} \mathrm{C}-300^{\circ} \mathrm{C}$ temperature range $(5 \mathrm{~min})$. Standard metallographic processes were carried out for microstructure examinations. Prepared specimens were etched with $100 \mathrm{ml} \mathrm{H}_{2} \mathrm{O}, 2 \mathrm{ml} \mathrm{HCl}$, $10 \mathrm{~g} \mathrm{FeCl}_{3}$ solution for $45 \mathrm{~s}$. The etched specimens were characterized by the scanning electron microscope and energy dispersive X-ray spectroscopy (SEM+EDS) and $\mathrm{X}$-ray diffraction (XRD).

\section{Results and discussion}

In Fig. 1 there are given microstructure SEM images of Sn-9Zn, Sn-9Zn-0.5/0.7/0.9 Al lead-free solder alloys.

From the microstructure SEM images in Fig. 1, it could be realized that $\mathrm{Sn}-9 \mathrm{Zn}$ alloy has an eutectic lamellar structure (Fig. 1a). Light colored regions in Sn-9Zn alloy were $\beta$-Sn phases. In some of previous studies, it was emphasized that the areas between the dark colored regions and the primary $\beta$-Sn phase were eutectic and that their structure were $\beta$-Sn rich [7]. Acicular and dark colored regions within the structure of the $\mathrm{Sn}-9 \mathrm{Zn}$ alloy were $\mathrm{Zn}$-rich areas. It was determined that addition of $\mathrm{Al}$ into the $\mathrm{Sn}-9 \mathrm{Zn}$ alloy resulted in thinning in $\mathrm{Zn}$ phases and Al-rich regions were formed (Fig. 1b-d). 


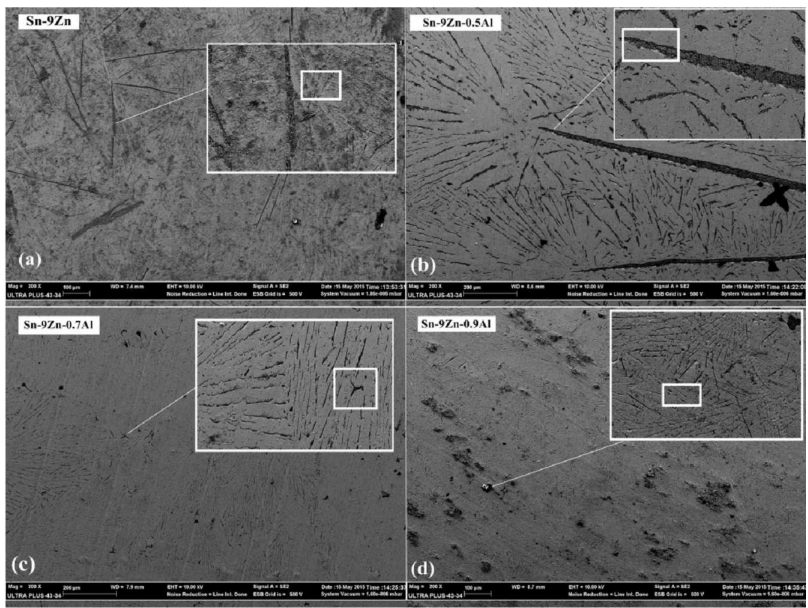

Fig. 1. SEM images of Sn-9Zn (a), Sn-9Zn-0.5Al (b), Sn-9Zn-0.7Al (c), Sn-9Zn-0.9Al (d) alloys.

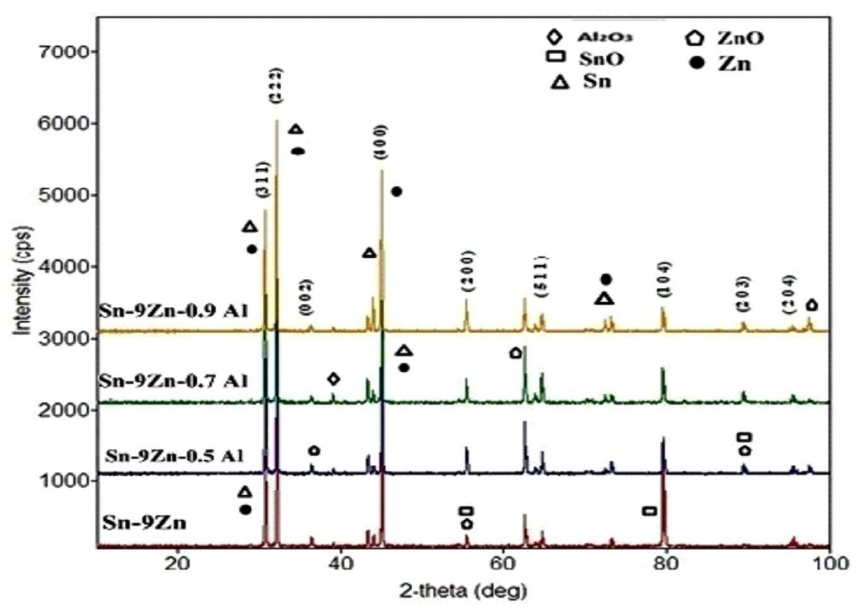

Fig. 2. XRD results of the $\mathrm{Sn}-9 \mathrm{Zn}$ and $\mathrm{Sn}-9 \mathrm{Zn}-x \mathrm{Al}$ alloys.
In Fig. 2 there are given XRD results of the eutectic Sn-9Zn alloys with added different amounts of Al. It was determined that $\mathrm{ZnO}, \mathrm{SnO}$, and $\mathrm{Al}_{2} \mathrm{O}_{3}$ phases were formed in the alloy structure according to the XRD results. The most important problem with $\mathrm{Sn}-\mathrm{Zn}$ based solders was that these alloys have low level of oxidation resistance [8]. $\mathrm{Zn}$ is highly inclined to oxidization; and $\mathrm{Zn}$ displays more inclination to oxidization at high temperatures in comparison with Sn [9]. Figure 3 shows the SEM images of Sn-9Zn- $x$ Al alloy afterwards of drop process. EDS results of $\mathrm{Sn}-9 \mathrm{Zn}-x \mathrm{Al}$ alloys are displayed in Table I.

TABLE I

EDS results of the $\mathrm{Sn}-9 \mathrm{Zn}$ and $\mathrm{Sn}-9 \mathrm{Zn}-x \mathrm{Al}$ alloys [wt.\%].

\begin{tabular}{c|c|c|c|c|c}
\hline \hline Alloy & Image & Sn & Zn & Al & O \\
\hline Sn-9Zn-0.7Al & Fig. 3a (1) & 77.53 & 11.70 & 1.41 & 9.36 \\
Sn-9Zn-0.9Al & Fig. 3b (2) & 44.09 & 22.75 & 1.77 & 31.39
\end{tabular}

According to given in Fig. 3a and b SEM images, it could be understood that shiny regions with light colour were oxides based on both the EDS and the XRD analysis. Melting temperature of $\mathrm{Sn}-9 \mathrm{Zn}$ eutectic alloy was so close to the $\mathrm{Sn}-\mathrm{Pb}$ solder alloy. However, $\mathrm{Zn}$ is active to the oxidization and it causes solder surface to oxidize easily by reducing surface tension and by reducing wettability of Sn-Zn solders during dropping [10]. Figure 4 exhibits contact angle results of the $\mathrm{Sn}-9 \mathrm{Zn}-x \mathrm{Al}(0.5-$ $0.9 \mathrm{Al}$ ) alloys at $215^{\circ} \mathrm{C}$.

According to the contact angle measurement results of $\mathrm{Sn}-9 \mathrm{Zn}-x \mathrm{Al}(0.5-0.9 \mathrm{Al})$ alloys given in Fig. 4 with respect to $215-230-250^{\circ} \mathrm{C}$, it was determined that addition of $\mathrm{Al}$ into the $\mathrm{Sn}-9 \mathrm{Zn}$ lead-free solder alloy adversely influenced wettability. The main cause of this was that addition of $\mathrm{Al}$ and increasing temperature resulted in formation of $\mathrm{SnO}, \mathrm{ZnO}$, and $\mathrm{Al}_{2} \mathrm{O}_{3}$ phases as accompanied by atmospheric environment.

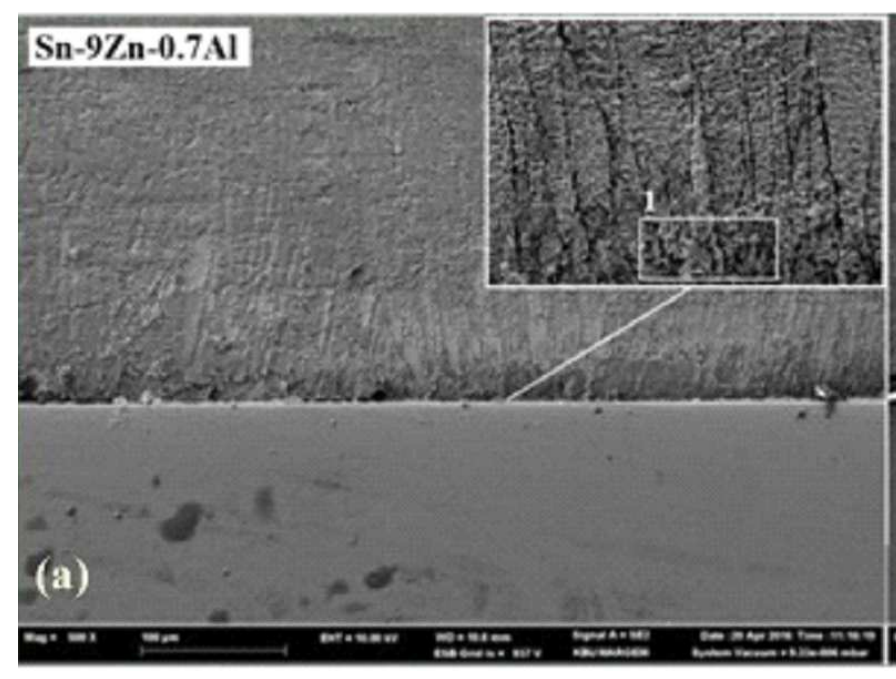

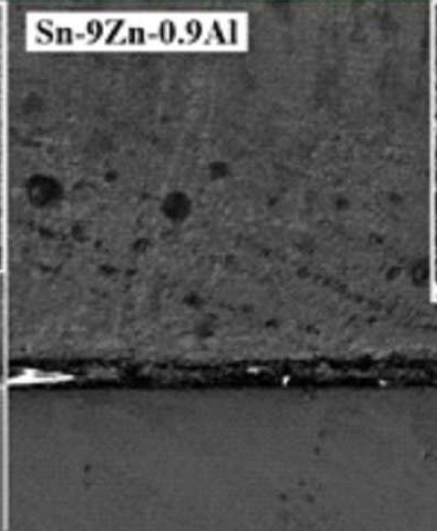

(b)

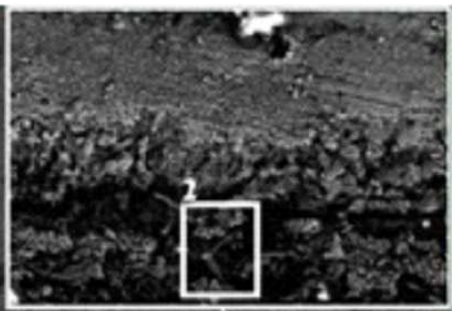

Fig. 3. SEM images of the $\mathrm{Sn}-9 \mathrm{Zn}-x \mathrm{Al}$ alloy afterwards of the drop process. 


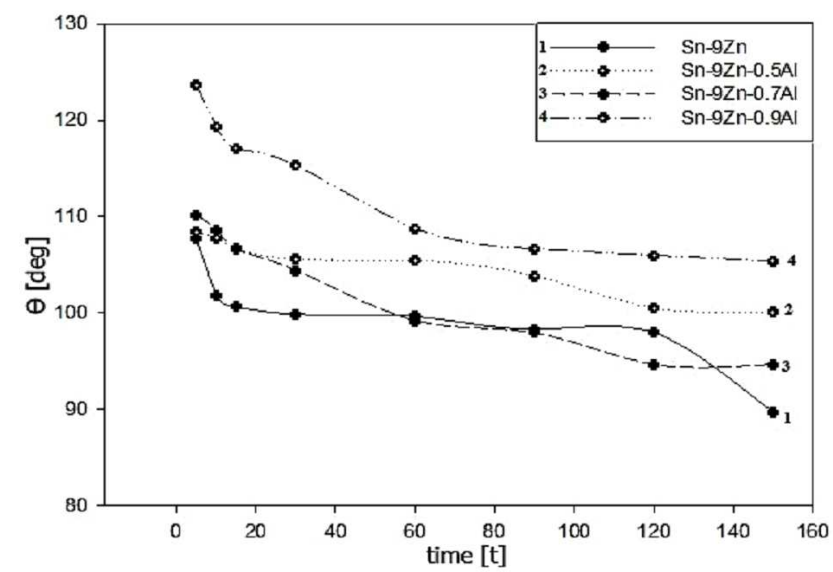

Fig. 4. Wetting results of the $\mathrm{Sn}-9 \mathrm{Zn}$ and the $\mathrm{Sn}-9 \mathrm{Zn}-$ $x \mathrm{Al}$ at $215^{\circ} \mathrm{C}$.

\section{Conclusion}

Sn-9Zn alloys exhibit lamellar eutectic structure. In microstructure examinations, it was determined that there were Zn-rich regions formed in the structure (acicular and dark-colored regions); and that addition of Al thinned these Zn-rich regions. Furthermore, oxidations were formed in the $\mathrm{Sn}-9 \mathrm{Zn}-x \mathrm{Al}$ alloys at three different temperatures $\left(\mathrm{SnO}, \mathrm{ZnO}\right.$, and $\mathrm{Al}_{2} \mathrm{O}_{3}$ ) (white and shiny regions). As a result of the characterization studies (SEM, EDS, and XRD), wetting capabilities of $\mathrm{Sn}-9 \mathrm{Zn}$ and $\mathrm{Sn}-9 \mathrm{Zn}-x \mathrm{Al}$ alloys were at low level due to oxidization.

\section{References}

[1] R.A. Islam, Y.C. Chan, W. Jillek, S. Islam, Microelectron. J. 37, 705 (2006).

[2] M. Abtew, G. Selvaduray, Mater. Sci. Eng. R. 27, 95 (2000).

[3] S.K. Das, A. Sharif, Y.C. Chan, N.B. Wong, W.K.C. Yung, J. Alloys Comp. 481, 167 (2009).

[4] D. Özyürek, B. Yavuzer, T. Tunçay, J. Adhes. Sci. Technol. 30, 1662 (2016).

[5] K.L. Lin, T.P. Liu, Oxidat. Met. 50, 314 (1998).

[6] J. Hashim, L. Looney, M.S.J. Hashmi, J. Mater. Process. Technol. 119, 324 (2001).

[7] S.C. Cheng, K.L. Lin, J. Electron. Mater. 31, 940 (2002).

[8] K. Suganuma, K.S. Kim, J. Mater. Sci. Mater. Electron. 121, 127 (2007).

[9] J. Jiang, J.E. Lee, K.S. Kim, K. Suganuma, J. Alloys Comp. 462, 244 (2008).

[10] S. Vaynman, M.E. Fine, J. Electron. Mater. 29, $1160(2000)$. 